\title{
Development of a Smartphone Overdependence Prevention Group Program in Adolescents
}

\author{
Eunsil Kim1), Hyundong Son2), Myeong-Ok Choi3), Buman Jeong4)
}

\begin{abstract}
The objective of this study was to design a group program to prevent smartphone overdependence in adolescents and verify its effects. The program comprises six sessions carried out in the following steps: "Building Relationships and Preparing for Change," "Preparing for Change," "Implementing Change," and "Maintaining Change." Furthermore, to verify its effects, we applied the program to 109 middle and high school students (51 in the experimental group, 58 in the control group) in Chungcheongnam-do. A significant difference was found in the scores of smartphone overdependence, peer relationships, and self-efficacy between the experimental group and the control group. This study showed that this short-term group program of six sessions had significant effects on reducing smartphone overdependence and improving peer relationships and self-efficacy. The program has significance in that it is a prevention program that reinforces the positive aspects of smartphone use as well as reduces the negative impact of smartphone overdependence.
\end{abstract}

Keywords : Smartphone, Overdependence, Prevention, Program, Peer, Relationships, Self-efficacy, Adolescents

\section{Introduction}

Adolescents experience great stress due to their studies or changes in their social environment. With a lack of alternative activities or activity spaces to relieve their stress, the use of smartphones is increasing due to their portability and accessibility and the variety of leisure activities they permit. Side effects such as smartphone overdependence or misuse are also growing, causing multiple problems and difficulties in daily life for adolescents[1][2]. These

Received(September 04, 2019), Review Result(1st: September 30, 2019, 2nd: November 07, 2019), Accepted(November 15, 2019)

1) (Professor) 31020 Dept. Child Welfare, Namseoul Univ., 91 Daehak-ro, Seonghwan-eup, Seobuk-gu, Cheonan, Chungcheongnam-do, Korea

email: gender@hanmail.net

2) (Professor, Corresponding Author) 61204 Dept. Education, Gwangju National Univ. of Education, 55 Pilmundaero, Pukgu, Gwangju, Korea

email: chamcoun@gnue.ac.kr

3) (Director) 41068 National Information Society Agency. 53, Sinhwa-ro Dong-gu Daegu, Korea email: cmo724512@nia.or.kr

4) (General manager) 41068 National Information Society Agency. 53, Sinhwa-ro Dong-gu Daegu, Korea email: cbm123@nia.or.kr 
difficulties appear in all aspects of their lives, including deterioration of physical health in the eyes, neck, shoulders, and wrists[3][4], changes in cerebral physiology such as "popcorn brain" or digital dementia[5], psychological problems like increased anxiety, depression, and aggression [6-9], relational problems like discord with family or friends and alienation[10], and school maladjustment[11].

Adolescents, in particular, face a high risk of smartphone overdependence, and adolescents are twice as likely as adults to be at risk of smartphone addiction[1]. As the negative impact of smartphone overdependence on adolescents has increased, studies on smartphone overdependence have been actively conducted since 2010. The government changed the Korean name of the Internet Addiction Prevention Center in 2015 to indicate its greater focus on smartphone usage. and adolescents are twice as likely as adults to be at risk of smartphone addiction. Moreover, the National Information Society Agency began using the term "smartphone overdependence" instead of "smartphone addiction" in 2014, thereby emphasizing the positive rather than the negative impacts of smartphone use, such as increased digital competence to receive all kinds of information in cyberspace, use it adequately in problem-solving, and share it with others. Its positive effects have also been shown by numerous studies, one of which determined that smartphone overdependence in adolescents reduces their vulnerability by improving their digital competence or relationships with others[12]. Thus, adolescents at high -risk for smartphone overdependence should not be approached merely as pathological cases, but rather considered competent to share information and communicate with others as well as reproduce digital content with smartphones[13]. Thus, for adolescents, smartphones are becoming a tool for a positive life, not the subject of addiction or a pathological phenomenon. Accordingly, it is necessary to take a preventive approach to encourage their positive use of smartphones by enhancing their digital competence rather than focusing only on the negative impact of smartphone usage.

However, most programs developed thus far have focused only on the issue of overdependence, which is why they seek to improve self-regulation in adolescents with smartphone overdependence. Moreover, while some studies found smartphone overdependence prevention programs to be effective[11][14-18], other researchers have argued that they were not[19][20], suggesting that the effectiveness of these programs depends on the characteristics of the research participants as well as the purpose and content of the programs and their theoretical background informing them. There have also been limitations because the programs were carried out in the form of lectures or a single-session one-time program.

Therefore, it is necessary to develop a prevention program that not only reduces smartphone 
overdependence but also promotes positive smartphone use. To prevent smartphone overdependence, it is particularly important to reinforce the motivations of adolescents[21-23], which has proved to be a critical approach in other fields of addiction besides smartphone overdependence. It is also necessary to promote what are known to be important protective factors against smartphone overdependence. Accordingly, the objective of this study is to design a group program for the prevention of smartphone overdependence in adolescents and verify its effectiveness. The research questions are as follows. First, what should constitute a group program for the prevention of smartphone overdependence of adolescents? Second, does a group program for the prevention of smartphone overdependence of adolescents have effects on their smartphone overdependence, self-efficacy, and peer relationships?

\section{Methods}

\subsection{Development of the Group Program to Prevent Smartphone Overdependence}

Our group program to prevent smartphone overdependence was developed based on the procedures proposed by Ahn[24]; we applied the program development process of VanZandt and Hayslip[25], and the procedures proposed by Park[26] as follows.

\subsubsection{Literature Review}

To develop the components of the group program for prevention of smartphone overdependence, we examined previous studies based on two main topics. We first reviewed the literature on risk and protective factors affecting smartphone overdependence[27-29] and smartphone overdependence prevention programs[11][14-20], determining that the important factors in preventing smartphone overdependence are self-esteem, motivation, self-efficacy, peer relationships, and parents' parenting behavior. Self-efficacy and peer relationships particularly improved adolescents' sense of belonging, bonding, self-esteem, self-control, and motivation, thereby effectively preventing smartphone overdependence.

\subsubsection{Needs Assessment}

A needs assessment was conducted to identify the content of a group program required to prevent smartphone overdependence involving in-depth interviews with 7 instructors at the Digital Overdependence Prevention Team in Chungnam and 10 adolescents with smartphone overdependence. The interview questions were: "What are the factors affecting smartphone 
overdependence?," "What content do you want the smartphone overdependence program to include?," and "What are the factors hindering healthy smartphone usage?" Qualitative analysis of the interviews showed that the program must include content that promotes the perception of smartphone misuse, strengthens bonding and a sense of belonging with peers, reinforces motivation, and cultivates self-efficacy.

\subsubsection{Formation of the Program Contents}

We devised the components of the program and the goal and contents of each session based on the literature review and needs assessment. The program comprises a total of six sessions: Session 1 "Building Relationships and Preparing for Change," Sessions 2-3 "Preparing for Change," Sessions 4-5 "Implementing Change," and Session 6 "Maintaining Change." The content validity of the program was verified by four experts (two professors of addiction counseling, one counselor, and one doctor of addiction counseling).

\subsubsection{Organization of the Program Contents}

The contents of the program were organized following the group program format of $\mathrm{O}^{\prime}$ Connor[30] as follows. In the Introduction of each session (5 minutes), the motivation of the participants was strengthened. In Development (35 minutes), the structured contents related to the goal of each session were carried out, and in the Conclusion ( 5 minutes), the participants exchanged feedback on the activities of each session. Each session took 45-50 minutes, which is equivalent to one period of class in school.

\subsubsection{Test Operation and Completion of the Final Version}

The developed program was test-operated with five middle school students to ensure the effectiveness of the content and management. The entire process was filmed with the consent of the participants and their guardians. The validity of the program contents, efficiency in management, and fidelity of interventions were evaluated through video feedback by two additional professors and one counselor acting as advisors. The contents and operating methods of the program were revised based on the evaluation of the advisors and feedback from the five participating students. [Table 1] shows the final version of the revised program.

\subsubsection{Implementation and Assessment of the Program}

To verify the effects of the final version of the program, we first selected four middle schools 
and one high school from the middle and high schools that applied for this program.

[Table 1] Contents of the Group Program for Prevention of Smartphone Overdependence

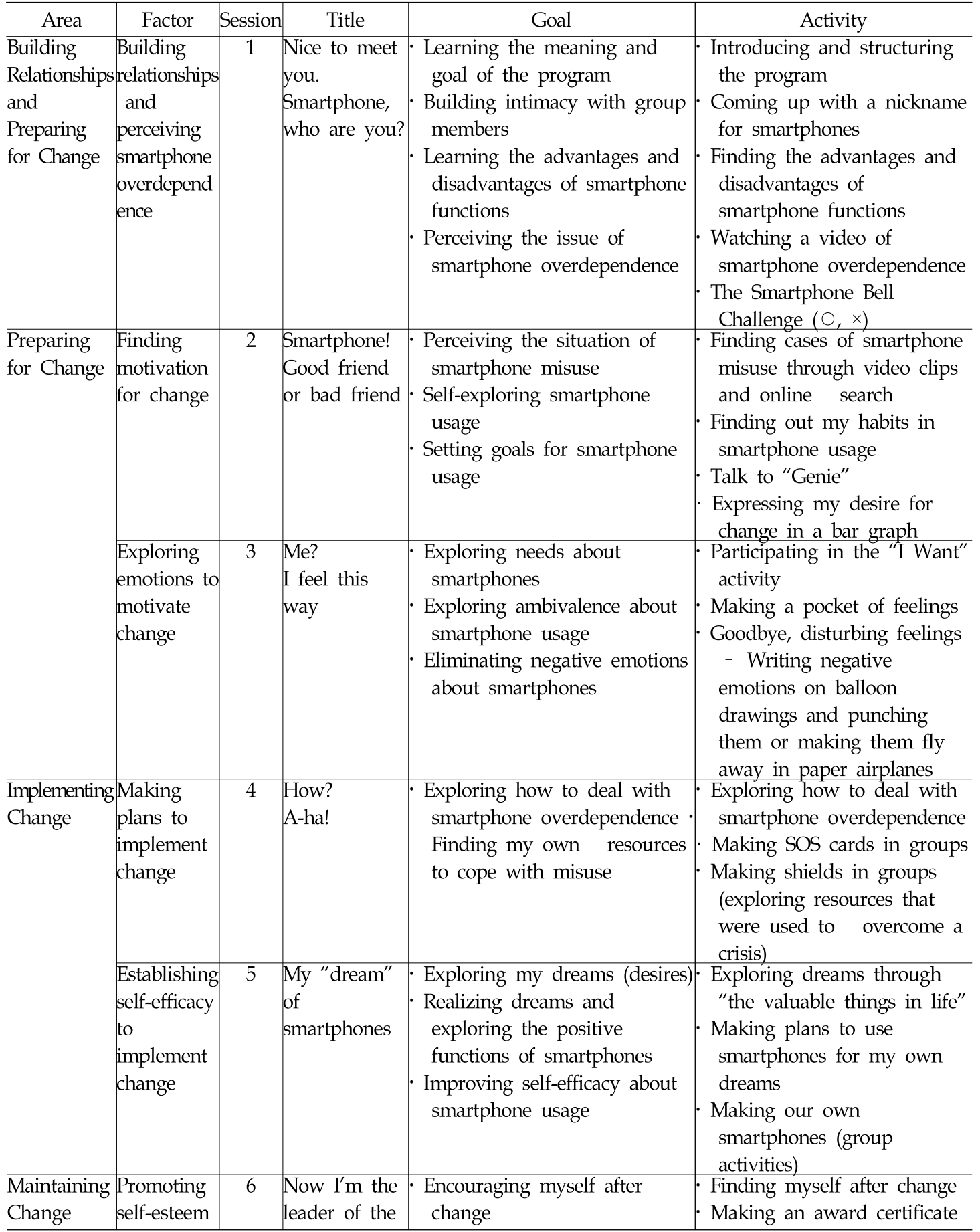




\begin{tabular}{l|l|l|l|l}
\hline & e-world! & $\begin{array}{l}\text { Building up the will for } \\
\text { healthy and sound } \\
\text { smartphone use }\end{array}$ & $\begin{array}{l}\text { for myself for changing } \\
\text { Writing a pledge to practice } \\
\text { healthy and sound } \\
\text { smartphone usage } \\
\text { Award certificate } \\
\text { presentation ceremony }\end{array}$ \\
\hline
\end{tabular}

Then, among students recommended by counselors and teachers of each school, we selected 109 students who wanted to participate in the program and obtained their parents' approval and then divided them into six groups (four middle school groups and two high school groups) with 7-10 students in each group. We conducted a pretest to determine the smartphone overdependence, peer relationships, and self-efficacy of the participants one week before starting the program. The program was carried out once a week from June to July 2019, with each session lasting 45-50 minutes. The entire process was filmed with the prior consent of the participants. Finally, participants were given the same test as the pretest one week after the program ended.

The fidelity of the program and validity of the operating method was verified by three experts (two addiction professors, and one counselor) through the video assessment carried out in Sessions 1, 3, and 6. The mean score for all items evaluated by the three experts was at least 4.5 , indicating that the program had fidelity and operated with validity.

\subsection{Participants}

A total of 109 students (43 male and 66 female) participated in the study, 75 of whom were middle school students (36 in the experimental group, 39 in the control group) and 34 high school students (15 in the experimental group, 19 in the control group); 38 middle school students were in their first year and 37 in their second year, while all high school students were in their first year.

\subsection{Tools}

Three tools were used in this study. First, the smartphone overdependence scale developed by Kwon and Aum[31] was used to determine smartphone overdependence. This scale comprises a total of 10 items rated on a 4-point scale, where higher scores indicate a higher risk of overdependence, and those with a total score of 31-40 are classified as the "high-risk group," 23 - 30 as the "at-risk group," and 10-22 as the "general group." The reliability (Cronbach's a) 
of this test was .89. Second, the peer relationship scale used in this study was a peer group social network scale with verified validity and reliability, based on the Network of Relationships Inventory (NRI) developed by Furman and Buhrmester[32] and adapted by Han[33]. It comprises a total of 33 items rated on a 5-point scale. The reliability (Cronbach's a) of this test was 93. Third, the self-efficacy scale used in this study was developed by Kim [34]. This scale has a total of 24 items rated on a 5-point scale. The reliability (Cronbach's $a$ ) of this test was 90 .

\subsection{Data Processing and Analysis}

A mixed ANOVA was used to verify the effectiveness of the program with two levels of pretest and posttest by testing time, as well as two levels of experimental and control by a group. A paired t-test was then conducted to determine whether there was a significant difference between the pretest and posttest scores of the experimental group and the control group. The significance level used in statistical verification was $5 \%$.

\section{Results}

\subsection{Smartphone Overdependence}

The results of the pretest and posttest for smartphone overdependence of the experimental and control groups show that the main effects of testing time and the group were all significant, as was their interaction (see Table 2). Thuis, there was a significant difference in smartphone overdependence changes between the experimental group and the control group.

[Table 2] Analysis of Smartphone Overdependence Changes of the Experimental and Control Groups

\begin{tabular}{|c|c|c|c|c|c|}
\hline Source of variance & SS & $d f$ & $M S$ & $F$ & $p$ \\
\hline \multicolumn{6}{|l|}{ Between-group } \\
\hline Group & 171.750 & 1 & 171.750 & 8.891 & .004 \\
\hline Error & 2066.966 & 107 & 19.317 & & \\
\hline \multicolumn{6}{|l|}{ Within-group } \\
\hline Testing & 262.281 & 1 & 262.281 & 9.041 & .003 \\
\hline Group $\times$ Testing time & 176.189 & 1 & 176.189 & 6.074 & .015 \\
\hline Error & 3103.940 & 107 & 29.009 & & \\
\hline Total & $5,781.126$ & 217 & 658.546 & & \\
\hline
\end{tabular}

More specifically, smartphone overdependence decreased significantly in the experimental 
group, while the control group did not show a significant change.

As shown in [Table 3] and [Fig. 1], the patterns of change in the mean values after participating in the program were different between the two groups:. While the experimental group showed a decrease in smartphone overdependence, the control group maintained the same level.

[Table 3] Descriptive Statistics and t-test Results for Smartphone Overdependence on the Pretest and Posttest

\begin{tabular}{llllll}
\hline Groups & Time & $M$ & $S D$ & $t$ & $p$ \\
\hline \multirow{2}{*}{$\begin{array}{c}\text { Experiment } \\
(\mathrm{n}=51)\end{array}$} & Pre & 23.94 & 7.27 & 2.79 & .006 \\
\cline { 2 - 5 } Control & Post & 19.94 & 5.17 & & .38 \\
$(\mathrm{n}=58)$ & Pre & 24.66 & 5.45 & .303 \\
\cline { 2 - 4 } & Post & 24.26 & 5.24 & & \\
\hline
\end{tabular}

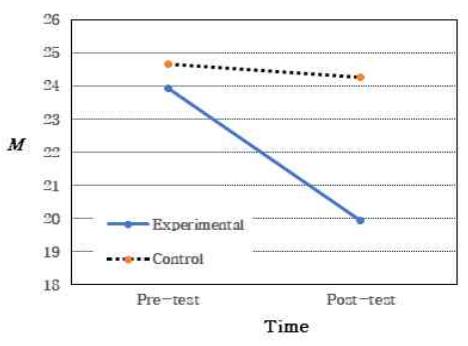

[Fig. 1] Means of the Comparison of Pretest-posttest Smartphone Overdependence

Therefore, in view of the results above, the smartphone overdependence of the experimental group decreased as a result of the program in which the experimental group participated.

\subsection{Peer Relationships}

The main effect of the group was not significant on the peer relationships of the two groups, but the main effect of testing time was significant (see [Table 4]). The interaction between group and time was also significant. This result shows that there was a significant difference in peer relationship changes between the experimental group and the control group.

[Table 4] Analysis of the Peer Relationship Changes of the Experimental-control Group

\begin{tabular}{|c|c|c|c|c|c|c|}
\hline Source of & variance & SS & $d f$ & $M S$ & $F$ & $p$ \\
\hline \multicolumn{7}{|l|}{ Between-group } \\
\hline Group & & 89.96 & 1 & 89.96 & .54 & .463 \\
\hline
\end{tabular}


Error

Within-group

Testing time

Group $\times$ Testing time

Error
17761.44

1309.68

2089.96

31933.66
107

$53,184.7$

http://dx.doi.org/10.21742/apjcri.2019.12.13

$$
166.00
$$

$1309.68 \quad 4.39$

7.00

2089.96

298.45

$3,954.05$

More specifically, peer relationships improved significantly in the experimental group, while the control group did not show a significant change. As shown in [Table 5] and [Fig. 2], the patterns of change in the mean values were different between the two groups after participating in the program. While the experimental group showed increased strength in peer relationships, the control group showed a decrease.

[Table 5] Descriptive Statistical Results for Peer Relationships in the Pretest and Posttest

\begin{tabular}{llllll}
\hline Groups & Time & $M$ & $S D$ & $t$ & $p$ \\
\hline $\begin{array}{l}\text { Experiment } \\
(\mathrm{n}=51)\end{array}$ & Pre & 108.10 & 22.34 & 2.69 & .010 \\
\cline { 2 - 5 } Control & Post & 111.19 & 18.98 & -0.52 & .605 \\
$(\mathrm{n}=58)$ & Pre & 112.48 & 15.89 & & \\
\cline { 2 - 5 } & Post & 111.19 & 13.30 & & \\
\hline
\end{tabular}

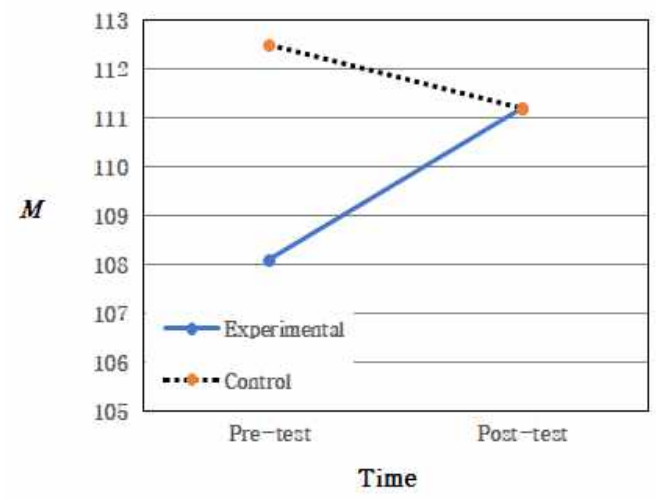

[Fig. 2] Means of the Comparison of Pretest-posttest Peer Relationships

Therefore, in view of the results above, the peer relationships of the experimental group improved as a result of the program.

\subsection{Self-efficacy}

The main effect of the group was not significant on the self-efficacy of the two groups, but the 
main effect of testing time was significant (see [Table 6]). The interaction between group and time was also significant. This result shows that there was a significant difference in self-efficacy changes between the experimental group and the control group.

[Table 6] Analysis of the Self-efficacy Changes of the Experimental and Control Groups

\begin{tabular}{|c|c|c|c|c|c|}
\hline Source of variance & $S S$ & $d f$ & $M S$ & $F$ & $p$ \\
\hline \multicolumn{6}{|l|}{ Between-group } \\
\hline Group & 11.71 & 1 & 11.71 & .137 & .712 \\
\hline Error & 9152.75 & 107 & 85.54 & & \\
\hline \multicolumn{6}{|l|}{ Within-group } \\
\hline Testing time & 2287.65 & 1 & 2287.65 & 11.52 & .001 \\
\hline Group $\times$ Testing time & 1741.59 & 1 & 1741.59 & 8.77 & .004 \\
\hline Error & 21256.51 & 107 & 198.66 & & \\
\hline Total & $34,450.21$ & 217 & $4,325.15$ & & \\
\hline
\end{tabular}

More specifically, self-efficacy improved significantly in the experimental group, while the control group did not show a significant change. The patterns of change in the mean values were also different: While the experimental group showed increased self-efficacy, the control group showed a decrease (see [Table 7] and [Fig. 3]).

[Table 7] Descriptive Statistical Results of the Pretest and Posttest of Self-efficacy

\begin{tabular}{clcccc}
\hline Groups & Time & $M$ & $S D$ & $t$ & $p$ \\
\hline \multirow{2}{*}{$\begin{array}{c}\text { Experiment } \\
(\mathrm{n}=51)\end{array}$} & Pre & 70.76 & 14.04 & 3.94 & .000 \\
\cline { 2 - 5 } $\begin{array}{c}\text { Control } \\
(\mathrm{n}=58)\end{array}$ & Post & 82.92 & 14.89 & & \\
\cline { 2 - 4 } & Pre & 77.09 & 12.99 & 0.35 & .726 \\
\hline
\end{tabular}

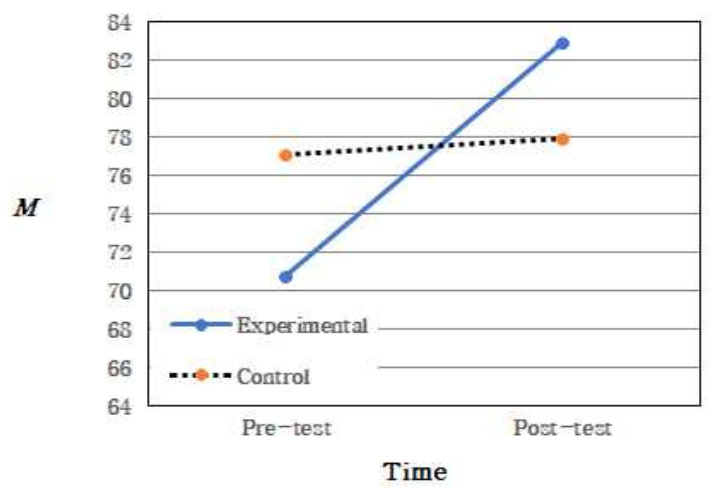

[Fig. 3] Means of the Comparison of Pretest-posttest Self-efficacy 
Therefore, in view of the results above, the self-efficacy of the experimental group improved as a result of the program.

\section{Discussion and Conclusion}

This study developed a group program for the prevention of smartphone overdependence in adolescents following standard program development procedures that we showed to have significant effects in reducing smartphone overdependence and improving peer relationships and self-efficacy. The results of this study are as follows.

First, this program is based on the reinforcement theory of motivation, whose effectiveness has been demonstrated in other fields of addiction. Moreover, self-efficacy, a protective factor of smartphone overdependence, was set as a component of the program based on the literature review. This program was also developed to reflect the needs of experts in the field, and its validity was improved with the participation of experts in content formation, test operation, and fidelity assessment. Thus, this program was systematically planned based on solid theoretical grounds. This program is also significant in being a short-term program with six sessions to help prevent smartphone overdependence by reinforcing protective factors rather than providing interventions to solve problems and eliminate the negative impact of smartphones, as other programs do.

Second, our results imply that the program was effective in reducing the smartphone overdependence of adolescents and improving their peer relationships and self-efficacy, which are protective factors of smartphone overdependence. First, the program helped adolescents break away from the negative impact of smartphone usage by reducing smartphone overdependence. This result may be due to improved self-efficacy and peer relationships because self-efficacy serves as a protective factor against other maladaptive behaviors of adolescents such as delinquency, school maladjustment, and school dropout, not only smartphone overdependence[35-38]. Furthermore, the program was carried out in groups, which promoted interactions with peers as well as a sense of belonging and bonding. This result is consistent with other research findings that, while many adolescents use smartphones to build relationships with peers, their smartphone overdependence decreases if they have better peer relationships[39-40] and smartphone addiction decreases as self-efficacy improves[41]. This result implies that group programs are as effective in preventing smartphone overdependence of adolescents as individual education or personal counseling. 
This study has several limitations that can be addressed in, further research. First, this program was developed by researchers based on a literature review and the needs of field experts; students only participated as beneficiaries of education. This is the same approach as that taken by the central government, public institutions, and older generations in finding solutions to smartphone overdependence. In our world, which is rapidly becoming characterized by hyperconnectivity and hyperintelligence, such a program must be formed and carried out in a way that helps adolescents take the initiative in solving problems using digital technology. This will more effectively prevent smartphone overdependence by enabling adolescents to display self-efficacy and promote collaboration skills through peer relationships. Second, we only conducted a quantitative analysis to verify the effectiveness of the group program. There is a need for an in-depth analysis of the effect of the program contents and components on individual subjects through qualitative research. Accordingly, it is necessary to develop a selective prevention program according to the characteristics of the subjects instead of applying a universal prevention program for everyone. Third, this program focuses on the psychosocial goal of improving peer relationships and self-efficacy. However, the rapid advancement of digital technology will usher in a world in which people can communicate beyond the limitations of time and space. In this world, people must have digital competence to properly judge all kinds of information available in cyberspace, adequately use it in problem-solving, and share it with others. Digital competence is a core competency required in the era of the Fourth Industrial Revolution that is, considered both a requirement and a right of citizens by the JRC-IPTS (the Institute for Prospective Technological Studies of the Joint Research Centre) of the EU. Therefore, it is necessary to develop a specialized program to enhance digital competence beyond a program that merely takes a psychological and relational approach.

\section{Acknowledgement}

Funding for this paper was provided by the Brain Research Program through the National Research Foundation of Korea by the Ministry of Science and ICT.

\section{References}

[1] J. M. Lim, S. J. Jang, M. Y. Lee and J. H. Lee, 2014 Internet usage survey, Ministry of Science, ICT and Future Planning \& Korea Internet \& Security Agency, (2015) 
[2] Giovanni Martinotti, Corrado Villella, Domitilla Di Thiene, Marco Di Nicola, Pietro Bria, Gianluigi Conte, Maria Cassano, Filippo Petruccelli, Nicola Corvasce, Luigi Janiri, Giuseppe La Torre, Problematic mobile phone use in adolescence: A cross-sectional study, Journal of Public Health, (2011), Vol.19, No.6, pp.545-551, DOI: 10.1007/s10389-011-0422-6

[3] J. S. Park, M. J. Choi, J. E. Ma, J. H. Moon and H. J. Moon, Influence of Cellular Phone Videos and Games on Dry Eye Syndrome in University Students, Journal of Korean Academy of Community Health Nursing, (2014), Vol.25, No.1, pp.12-23, DOI: 10.12799/jkachn.2014.25.1.12

[4] Y. S. Choi, A study on mobile phone addiction and physical pain based on characteristics of mobile phone usage, Journal of Medical Imaging and Health Informatics, (2019), Vol.9, No,6, pp.1191-1195, DOI: 10.1166/jmihi.2019.2716

[5] H. J. Findlay, H. E. Findlay, Mobile technologies transforming the brain and impacting various aspects of societal life, Journal of Healthcare, Science and the Humanities, (2014), Vol.5, No.2, pp.93-113.

[6] S. Y. Kim, C. R. Nho and Y. K. Son, The effects of adolescents' mobile phone dependency on depression and aggression: the mediating effects of parenting attitudes and peer relationships, Korean Journal of Social Welfare Studies, (2016), Vol.47, No.3, pp.251-277, DOI: 10.16999/kasws.2016.47.3.251

[7] J. D. Elhai, R. D. Dvorak, J. C. Levine and B. J. Hall, Problematic smartphone use: A conceptual overview and systematic review of relations with anxiety and depression psychopathology, Journal of Affective Disorders, (2017), No.207, pp.251-259, DOI: 10.1016/j.jad.2016.08.030

[8] Enez Darcin Asli, Kose Samet, Noyan Cemal Onur, Nurmedov Serdar, Yılmaz Onat, Dilbaz Nesrin, Smartphone addiction and its relationship with social anxiety and loneliness, Behaviour \& Information Technology, (2016), Vol.35, No.7, pp.520-525, DOI: 10.1080/0144929X.2016.1158319

[9] M. O. Kim, H. Kim, K. Kim, S. Ju, J. Choi and M. Yu, Smartphone addiction: Focused depression, aggression and impulsion among college students, Indian Journal of Science and Technology, (2015), Vol.8, No.25, pp.1-6, DOI: 10.17485/ijst/2015/v8i25/80215

[10] H. S. Kim and S. H. Byun, Impact of smartphone addiction of adolescents peer relationships, Asia-Pacific Journal of Business Venturing and Entrepreneurship, (2015), Vol.10, No.5, pp.117-125, DOI: 10.16972/apjbve.10.5.201510.117

[11] Y. S. Lee, E. Y. Kim, L. S. Kim and Y. H. Choe, Development and effect evaluation of smartphone addiction prevention program for adolescent, The Korea Journal of Youth Counseling, (2014), Vol.22, No.1, pp.303-334, DOI: 10.35151/kyci.2014.22.1.013

[12] N. S. Jung, M. O. Choi, Y. S. Lee, H. N. Ahn, Development of internet vulnerability index for youth through internet overdependency analysis, The Journal of the Korea Contents Association, (2019), Vol.19, No.4, pp.345-358, DOI: 10.5392/JKCA.2019.19.04.345

[13] H. N. Ahn, M. O. Choi, Y. S. Kim and N. S. Jung, Adolescents motivation and digital literacy according to the level of internet over-dependency, The Journal of Learner-Centered Curriculum and Instruction, (2019), Vol.19, No.6, pp.1345-1363, DOI: 10.22251/jlcci.2019.19.6.1345

[14] H. Y. Koo, Effects of a prevention program for media addiction on television addiction, internet addiction, cellular addiction, and impulsiveness in elementary school students, Child Health Nursing Research, (2013), Vol.19, No.4, pp.270-281, DOI: 10.4094/chnr.2013.19.4.270 
[15] M. A. Seong, H. K. Yu, and S. I. Nam, Development of a group counseling program to prevent the smartphone addiction in a potential risk group of high school students, The Journal of Learner-Centered Curriculum and Instruction, (2015), Vol.15, No.8, pp.185-203, UCI: G704-001586.2015.15.8.008

[16] S. R. Jeong, H. K. Yu and S. I. Nam, Development of a group counseling program to prevent addiction to smart-phones in a potential risk group of middle school students, Korea Journal of Counseling, (2014), Vol.15, No.3, pp.1145-1162, DOI: 10.15703/kjc.15.3.201406.1145

[17] C. W. Lim, G. C. Jeong, Development and effectiveness verification of smartphone game addiction prevention program for adolescents, Korean Journal of Addiction Psychology, (2016), Vol.1, No.1, pp.67-84.

[18] J. Y. Lee and H. K. Yu, Development of a group counseling program to reduce cellular phone addiction tendency of elementary school students in higher grade, The Korean Journal of Educational Methodology Studies, (2013), Vol.25, No.1, pp.29-49, DOI: 10.17927/tkjems.2013.25.1.29

[19] H. Y. Koo, Development and effects of a prevention program for cell phone addiction in middle school students, Child Health Nursing Research, (2011), Vol.17, No.2, pp.91-99, UCI: G704-001009.2011.17.2.008

[20] M. S. Kim, E. M. Choi, S. H. Lee and J. H. Bae, Development and preliminary outcome study of smartphone overuse prevention education program for adolescents of middle school, Journal of Information Technology Service, (2013), Vol.12 No.4, pp.307-318, DOI: 10.9716/KITS.2013.12.4.307

[21] S. A. Kim and D. H. Lee, Effects of a motivational Interviewing group program for SNS addiction-prone middle school girls on their motivation for change and healthy smartphone, The Korea Journal of Youth Counseling, (2017), Vol.25, No.2, pp.253-271, DOI: 10.35151/kyci.2017.25.2.012

[22] B. W. Lundahl, C. Kunz, C. Brownell, D. Tollefson, and B. L. Burke, A meta-analysis of motivational interviewing: Twenty-five 146 years of empirical studies, Research on Social Work Practice, (2010), Vol.20, No.2, pp.137-160, DOI: $10.1177 / 1049731509347850$

[23] S. Naar-King and M. Suarez, Motivational interviewing with adolescents and young adults, The Guilford Press, (2011)

[24] I. H. Ahn, Development and Challenges for the Group Counseling Program in Elementary School, The Korean Journal of Elementary Counseling, (2011), Vol.10, No.1, pp.57-76, UCI : G704-SER000003102.2011.10.1.002

[25] Z. VanZandt and J. Hayslip, Developing your school counseling program: A handbook for systemic planning, Brooks/Cole Thompson Learning, (2001)

[26] I. W. Park, Systematic model for developing an effective group counseling program, Keimyung University, Student Life Research Institute, (1995), Vol.20, pp.19-40.

[27] N. Park, Y. C. Kim, H. Y. Shon, and H. Shim, Factors influencing smartphone use and dependency in South Korea, Computers in Human Behavior, (2013), Vol.29, No.4, pp.1763-1770, DOI: 10.1016/j.chb.2013.02.008

[28] Sam-Wook Choi, Dai-Jin Kim, Jung-Seok Choi, Heejune Ahn, Eun-Jeung Choi, Won-Young Song, Seohee Kim, Hyunchul Youn, Comparison of risk and protective factors associated with smartphone addiction and Internet addiction, Journal of Behavioral Addictions, (2015), Vol.4, No.4, pp.308-314, DOI: 10.1556/2006.4.2015.043

[29] Yejin Kim, Jo-Eun Jeong, Hyun Cho, Dong-Jin Jung, Minjung Kwak, Mi Jung Rho, Hwanjo Yu, Dai-Jin 
Kim, In Young Choi, Personality factors predicting smartphone addiction predisposition: Behavioral inhibition and activation systems, impulsivity, and self-control, PloS One, (2016), Vol.11, No.8, e0159788, DOI: 10.1371/journal.pone.0159788

[30] K. J. O'Connor, The play therapy primer: An integration of theories and techniques, 2nd Edition, Wiley, (2000)

[31] S. J. Kwon and N. R. Aum, 2016 Digital Culture Forum Policy Research Report: Smartphone overdependence scale reorganization final report, Daegu: National Information Society Agency, (2016)

[32] W. Furman and D. Buhrmester, Children's perceptions of the qualities of sibling relationships, Child Development, (1985), Vol.56, No.2, pp.448-461, DOI: 10.1111/J.1467-8624.1985.TB00119.X

[33] J. H. Han, Influences from the social network of relationships on children's self-perceived competence and self-esteem, Kyeonghee University, Doctoral Dissertation, (1996)

[34] A. Y. Kim, Study on the academic failure-tolerance and its correlates, The Korean Journal of Educational Psychology, (1997), Vol.11, No.2, pp.1-19.

[35] W. K. Kim, The effects of psychological factors in suicidal ideation among Korean youth, Studies on Korean Youth, (2014), Vol.25, No.3, pp.199-231, DOI: 10.14816/sky.2014.25.3.199

[36] S. E. Roh amd J. H. Kim, The influence of social factors of crisis youth on addiction: Focused on moderating effects of self-efficacy, Korean Association of Addiction Crime Review, (2017), Vol.7, No.4, pp.23-41, DOI: 10.26606/kaac.2017.7.4.2

[37] H. Chung and M. Elias, Patterns of adolescent involvement in problem behaviors: Relationship to self efficacy, social competence, and life events, American Journal of Community Psychology, (1996), Vol.24, No.6, pp.771-784, DOI: 10.1007/BF02511034

[38] A. Carroll, K. Gordon, M. Haynes and S. Houghton, Goal setting and self-efficacy among delinquent, at-risk and not at-risk adolescents, Journal of Youth and Adolescence, (2013), Vol.42, No.3, pp.431-443, DOI: $10.1007 / \mathrm{s} 10964-012-9799-y$

[39] K. T. Kim, H. J. Lee, and S. I. Moon, Exploring the effects of network size, usage behaviors, and assimilation for peer relations on adolescents' smartphone addiction symptoms, Korean Journal of Broadcasting and Telecommunication Studies, (2016), Vol.30, No.4, pp.5-40, UCI: G704-000045.2016.30.4.003

[40] C. B. Cho, The Effect of Peer Relationship of Adolescents and Smartphone Addiction: Focused on the Mediating Effect of Depression, Korean Journal of Social Welfare Research, (2017), Vol.52, pp.5-34, DOI: 10.17997/SWRY.52.1.1

[41] G. W. Jung and J. H. Kim, The mediating effect of self-efficacy on parental attachment, peer attachment, and smart phone addiction in middle school students, The Korean Journal of Rehabilitation Psychology, (2016), Vol.23, No.3, pp.599-614, UCI: G704-SER000009521.2016.23.3.008 